\title{
Research on the International Cooperation Mechanism for the Construction of the China-Mongolia-Russia Economic Corridor under the Background of the COVID-19 Epidemic
}

\author{
Nan Yan \\ Harbin University of Commerce, Harbin, China \\ *Corresponding author. Email: 83566986@qq.com

\begin{abstract}
This article takes the China-Mongolia-Russia Economic Corridor as the research object, analyzes the adverse impact of the COVID-19 epidemic on its construction, and proposes an international cooperation mechanism for the high-quality construction of the China-Mongolia-Russia Economic Corridor. The international cooperation mechanism starts from the objectives and construction principles, and the content includes the international cooperation mechanism of joint prevention and control, coordinated promotion mechanism, risk prevention and control mechanism, and guarantee mechanism. It hopes to provide a reference for the promotion of regional economic cooperation in the "post-epidemic era" and the improvement of the construction of "The Belt and Road Initiatives".
\end{abstract}

Keywords: the COVID-19 epidemic, China-Mongolia-Russia economic corridor, international cooperation

mechanism, prevention and control measures

\section{INTRODUCTION}

The outbreak and spread of the COVID-19 epidemic is the most serious public health event after the SARS in 2003 and the Middle East respiratory syndrome in 2012. Its scope of influence, number of infections and impact on the global economy, society and politics are unprecedented. As of September 15, 2020, Beijing time, the cumulative number of confirmed cases of the epidemic infections worldwide has reached nearly 30 million, and the death toll is close to 100,000 . Although China was the first country to be hit by the epidemic, under the strong leadership of the party and government, through effective prevention and control measures, the epidemic of China was effectively contained as early as March [1-2].

Coordinating the prevention and control of the epidemic and promoting the full resumption of work and production are the primary tasks of the Chinese government. "The Belt and Road Initiatives" that was suspended due to the epidemic in the first half of the year should press the "restart button" to start construction under the preconditions of epidemic prevention and control. The "China-Mongolia-Russia Economic Corridor" is one of the six major economic corridors of the Belt and Road Initiatives, and its early construction has achieved fruitful results. China, Russia and Mongolia are adjacent to each other and have a stable and long-term economic and trade cooperation basis. In addition, Mongolia is less affected by the epidemic [3-4]. The infection rate of the epidemic in the Russian Far East is not high. Therefore, ChinaMongolia-Russia Economic Corridor has the conditions to be the first to open the "resumption button". However, before there's no specific drugs and vaccines, the development of the epidemic will still be confusing, and human society must be prepared for a long-term struggle against it. In the context of the normalization of epidemic prevention and control, it is now more necessary for countries around the world to strengthen close cooperation and coordinate the promotion of epidemic prevention and control and economic and social development.

\section{THE IMPACT OF THE COVID-19 EPIDEMIC ON THE CONSTRUCTION OF THE CHINA-MONGOLIA-RUSSIA ECONOMIC CORRIDOR}

(1) The supply of labor and capital for construction is hindered, and the business is in danger of bankruptcy. The prevention and control of the epidemic needs to locate the source of infection as soon as possible and quickly block the transmission route. Therefore, the isolation of key personnel has become the most effective means of prevention and control. However, this measure also cuts off the way for labor to participate in the production and operation of enterprises. Companies are forced to suspend production and face production and operation difficulties. 
Some small, medium and micro enterprises have already closed down in the early or mid-stage of the epidemic. If the surviving companies cannot obtain sufficient financial support, most of them have the risk of capital chain disconnection.

(2) The project construction cycle is forced to lengthen, risks increase, costs rise, and yields decline. The international cooperation projects in the construction of the China-Mongolia-Russia Economic Corridor are basically based on capacity cooperation projects such as infrastructure, energy and chemical engineering, and equipment manufacturing. The investment cycle is long, the risk is high, and there are problems with unclear investment returns. Coupled with the impact of the epidemic, the construction cycle of many international capacity cooperation projects in the future may continue to lengthen, and the risk of epidemic prevention and control will increase, and the construction cost will rise, which will lead to a decline in investment yield.

(3) The industrial chain and supply chain have a chain disconnection crisis. The core links of the industrial chain and supply chain of most of the international capacity cooperation projects constructed in the China-MongoliaRussia Economic Corridor are located in China .In the first quarter of this year, the transportation and logistics industry in China primary product processing industry and equipment manufacturing industry are basically in a shutdown or semi-stop state, which directly threatens the supply of raw materials and industrial products required for the construction of international capacity cooperation projects [5-6]. However, since the second quarter, China has entered the stage of full resumption of work and production, but Russia has become the hardest-hit area of the epidemic, and most of the international production cooperation projects located in Russia were once again forced to suspend production. The spread of the epidemic has blocked the supply of raw materials, semi-finished products and finished products, and has seriously threatened the stability and safety of the existing industrial chain and supply chain.

Faced with the above-mentioned shocks and risks, how the China-Mongolia-Russia Economic Corridor accomplishes high-quality construction tasks under the background of "normalization of epidemic prevention and control" needs to be guaranteed by an international cooperation mechanism. The following will discuss the objectives of the international cooperation mechanism, the construction principles and the content of the mechanism construction.

\section{OBJECTIVES OF THE INTERNATIONAL COOPERATION MECHANISM}

(1) The overall goal is to jointly build a human health community. The disease spreads regardless of national borders or race, and people in all countries, rich or poor, are exposed to the scope of the COVID-19 infection. Nowadays, the COVID-19 is still spreading rapidly around the world, and governments and people of all countries must join hands to fight the common enemy of the epidemic. China, Mongolia and Russia, as friendly neighbors separated by a thin strip of water, should join hands to fight the epidemic together. Therefore, the establishment of an international cooperation mechanism should take the joint construction of a human health community as the overall goal, and the establishment of an international cooperation mechanism for joint prevention and control of the COVID-19 epidemic as the primary task. (2) Accelerate the resumption of work and production, and realize the high-quality construction of the ChinaMongolia-Russia Economic Corridor. The hard-won achievement of the early construction of the ChinaMongolia-Russia Economic Corridor is the result of the long-term efforts of the governments and enterprises of the three countries to build. It must not be abandoned because of the impact of the epidemic. As the epidemic situation in China is under preliminary control and the epidemic situation in Mongolia is relatively mild, the ChinaMongolia-Russia Economic Corridor construction project that meets the requirements of epidemic prevention and control should be promoted as soon as possible to resume work and production, and a corresponding promotion mechanism should be established to promote the continued construction of projects under construction. The project will be implemented as soon as possible and try to make up for the various losses caused by the previous shutdown.

(3) With the construction of the China-Mongolia-Russia Economic Corridor as the core, the "Silk Road Economic Belt" will resume work and production. Make full use of the Sino-Russian and Sino-Mongolian bilateral international cooperation mechanisms to further expand industrial cooperation with Russia and Mongolia. At the same time, strengthen practical cooperation with countries in Central Asia and West Asia in manufacturing, agriculture, and modern service industries. In the "postepidemic era", adhere to the principle of mutual benefit, continue to open the China-Europe railway, improve the level of China-Mongolia-Russia land transportation infrastructure, and unblock the logistics channels of ChinaEurope and Central Asia to provide economic revitalization for countries along the "Silk Road Economic Belt" Guaranteed.

\section{PRINCIPLES FOR BUILDING INTERNATIONAL COOPERATION MECHANISMS}

(1) In line with the general requirements of epidemic prevention and control in various countries, adhere to the general principle of steadily advancing after easy first and then difficult. At present, many international cooperation projects in the construction of China-Mongolia-Russia Economic Corridor are in a state of suspension. Under the background of uncertain prospects for international epidemic prevention and control, mechanism construction must meet the general requirements of China, Mongolia 
and Russia for epidemic prevention and control. Under the premise of fully guaranteeing people's lives and health, mechanism construction can give priority to construction projects that are less difficult, less labor-intensive, and relatively closed.

(2) Adhere to the principle of coordinated advancement of epidemic prevention and control and speeding up the resumption of work and production of international cooperation projects. Mechanism construction should be conducive to international cooperation in epidemic prevention and control and speeding up the resumption of work and production of bilateral and multilateral cooperation projects, and the two tasks should be advanced simultaneously. The construction of the mechanism should focus on accelerating the construction of major and key projects in the China-Mongolia-Russia Economic Corridor, and determine an international cooperation plan for epidemic prevention and control.

(3) Adhere to the principle of establishing a closer international cooperation relationship between enterprises and the government for epidemic prevention and control. The international economic situation in the "post-epidemic era" will become more complex and changeable, and it is difficult to judge whether the spread of the international epidemic can be effectively contained. In the "postepidemic era", the degree of cooperation between companies in different countries and international governments will determine the key to whether the international economy can quickly emerge from the haze of the epidemic in the future. Therefore, mechanism construction should be conducive to the establishment of closer international economic cooperation relations between enterprises and governments.

\section{THE CONTENT OF INTERNATIONAL COOPERATION MECHANISM CONSTRUCTION}

(1) Establish an international cooperation mechanism for joint prevention and control of the COVID-19 epidemic. First of all, under the guidance of the World Health Organization, an epidemic prevention and control working group led by the health and epidemic prevention departments, customs departments, and foreign affairs departments of China, Mongolia, and Russia shall be established as soon as possible to coordinate the joint epidemic prevention and control work of the three countries; Second, establish an epidemic notification channel at border ports. When an epidemic is detected at the port, it should immediately use the dedicated communication channel to directly report to the customs and health and epidemic prevention departments of the country on the other side to reduce the reporting time at all levels. For newly discovered and suspected cases, other countries are allowed to adopt compulsory quarantine measures for their citizens without discrimination; third, adopt a unified the COVID-19 test standard and recognize the test report. Citizens of China, Mongolia, and Russia who enter and exit the country by land, water or air transportation are allowed to enter and exit the country as long as they have a "new crown pneumonia" nucleic acid test report issued by the health and epidemic prevention department on the same day.

(2) Establish a coordinated promotion mechanism to coordinate the prevention and control of epidemic and the high-quality construction of the China-Mongolia-Russia Economic Corridor. As soon as possible, establish a highquality construction work group for the China-MongoliaRussia Economic Corridor, led by the commerce departments and customs departments of China, Mongolia, and Russia, and composed of industry associations and key enterprises. The working group composed of industry associations and key enterprises is responsible for sorting out the international cooperation projects impacted by the epidemic, and counting the losses suffered. The working group led by the Ministry of Commerce and customs departments of the three countries is responsible for the overall arrangement of international cooperation projects for the resumption of work and production, and proposes policies and measures to help companies respond to the impact of the epidemic and resume work and production.

(3) Establish the epidemic risk prevention and control mechanism for the high-quality construction of the ChinaMongolia-Russia Economic Corridor. The epidemic has had a huge impact on the international trade and investment activities between China and Mongolia, China and Russia. Due to the concealed and instantaneous nature of the epidemic, its risk prevention and control are particularly important. An epidemic risk prevention and control network needs to be established. The government should assist companies in accurately identifying various business risks brought about by the epidemic, assessing the impact of risks, establishing a risk early warning mechanism, proposing risk response plans, and building a three-level risk prevention and control mechanism from government departments, industry associations to enterprises.

(4) At the beginning of the epidemic in China, due to the rapid increase in the number of infected people in a short period of time, there was a temporary shortage of supplies of epidemic prevention materials. The international community has extended a helping hand, especially countries along the Belt and Road Initiatives have donated a large number of anti-epidemic materials such as masks, medical protective clothing and medicines to China. China, where the epidemic has been initially brought under control and has fully resumed work and production, is now able to make its own contributions to international health and epidemic prevention and assume corresponding international responsibilities. Establish a high-quality construction of the COVID-19 epidemic prevention and control mechanism for the China-Mongolia-Russia Economic Corridor. As the world's largest production base for health and anti-epidemic materials, China continues to export high-quality anti-epidemic materials to countries in need of the world, and gives priority to meeting the procurement needs of countries along "The Belt and Road Initiatives" such as Russia and Mongolia to provide 
protection for epidemic prevention and control. More importantly, in the field of the COVID-19 vaccine and drug development, scientists from China and Russia should strengthen international cooperation. After the vaccine is successfully developed, it will be provided to the global market as an international public good that benefits people all over the world.

\section{CONCLUSION}

The epidemic has prolonged the construction period of the China-Mongolia-Russia Economic Corridor, hindering the supply of labor and capital, and putting the industrial chain and supply chain at risk of rupture. In the normalization stage of epidemic prevention and control, an international cooperation mechanism should be established to promote the construction of the China-Mongolia-Russia Economic Corridor. Adhering to the general principle of easy first, difficult later, and steady progress, a joint epidemic prevention and control mechanism; a coordinated promotion mechanism; a risk prevention and control mechanism and a guarantee mechanism should be established. The establishment of these mechanisms will promote the development of the China-Mongolia-Russia Economic Corridor towards higher quality, faster speed and stronger anti-risk capabilities. It hopes to provide a reference for the promotion of regional economic cooperation in the "post-epidemic era" and the improvement of the quality of "The Belt and Road Initiatives" construction.

\section{ACKNOWLEDGMENT}

The study was financially supported by National Social Science Fund Project "Study on the Establishment of China-Eurasian Economic Union FTA under the Vision of the Silk Road Economic Belt" (No:18BJL094).

\section{REFERENCES}

[1] Zhou Meifang, Liu Yu, Zhang Jinzhu, Cui Qi. Study on the Macroeconomic Effects of the New Coronary Pneumonia Epidemic and the Effectiveness of Response Policies[J]. Journal of Quantitative and Technical Economics,2020,37(08):24-41.

[2] Ding Renzhong, Li Yu, Li Biao. How to resume work and production under the new crown pneumonia epidemic: From the perspective of the industry chain $[\mathrm{J}]$. Finance and Economics, 2020(05):65-76.

[3] Cai Chunlin, Zhang Shuang. "Fighting the Epidemic and Stabilizing the Economy" topic (3) Suggestions for Guangdong foreign trade enterprises to resume work and stabilize production after the new crown pneumonia epidemic [J]. Guangdong Economy, 2020(03):14-21.

[4] Wu Changnan, He Xiuling. Coordinating and promoting research on epidemic prevention and control and economic development in Fujian [J]. Fujian Forum (Humanities and Social Sciences Edition), 2020(04):3440.

[5] Xiang Yijun, Zhou Yixin. Advancing China's international production capacity cooperation in the new era: new models, new mechanisms and new paths $[\mathrm{J}]$. Business Research, 2018(10):1-9.

[6] Qian Jinyu. Modern urban epidemic prevention and control from the perspective of risk management [J]. Theoretical Exploration, 2020(03): 22-30. 